DOI 10.22394/1818-4049-2018-84-3-142-148

УДК 343.9:328.185

\title{
Ф. Ф. Смирнов
}

\section{Совершенствование антикоррупционного обучения дОАЖнОстныХ АНЦ}

$\boldsymbol{B}$ статье автором предпринята попытка рассмотреть современное состояние профрессиональной подготовки должностных лии фредерального, регионального и мунииипального уровней, участвующих в рамках своих полномочий в противодействии коррупиии, $m$. е. тех, кто организует и реализуют соответствующие профрилактические мероприятия (сотрудники кадровых подразделений), а также остальных должностных лии, выполняюших требования антикоррупиионного законодательства. На основе существуюшего положительного опыта подготовки кадров в сфере противодействия терроризму, автором определён перечень направлений, с помощью которых возможна эфррективная профрессиональная подготовка сотрудников федерального, регионального и мунииипального уровней, участвуюших в рамках своих полномочий в противодействии коррупиии. В их числе: программь профрессиональной переподготовки и повышения квалификации; обучающие семинары; межведомственные учебно-практические курсы; учебно-методические сборы; тренинги и деловые игры; проведение стажировок в компетентных органах власти, непосредственно занимаюшихся профилактикой коррупиии, аппаратах администраиий и органов власти субъектов Российской Федераиии; наставничество при прибытии на государственную и мунииипальную службу вновь назначенных сотрудников; самообучение. Также автором предложена корректировка действуюшего законодательства в части, касающейся организаиии профрессиональной подготовки сотрудников федеральных органов исполнительной власти, органов исполнительной власти субъектов Российской Федераиии и органов местного самоуправления, участвуюших в рамках своих полномочий в противодействии коррупиии.

ключевые слова: коррупиия, противодействие коррупиии, подготовка кадров, антикоррупиионая деятельность, правовое регулирование, совершенствование.

Профессионально подготовленные кадры являются кАючевым фактором эффективности системы противодействия коррупции. При этом задача кадрового обеспечения антикоррупционной деятельности особенно актуальна в условиях недостаточной правовой и профессиональной подготовки сотрудников федеральных и региональных органов исполнительной власти, органов местного самоуправления, участвующих в реамизации мероприятий по профилактике коррупции, то есть именно тех, в чьей непосредственной компетенции находятся вопросы противодействия данному негативному социальному явиению.

Отсутствие необходимых знаний, навыков и умений, недостаточная во- влеченность в процесс реализации профилактических мероприятий, низкий уровень контроля и требовательности к выполнению положений антикоррупционного законодательства -это условия для снижения уровня организации противодействия коррупции, и, как следствие, создание благоприятной среды для совершения коррупционных посягательств. [Рогов, 2011. С. 22-27 ; Рогов, Нестеров, 2015. С. 182-184 ; Шедий, 2010. С. 125-131 ; Авдеев, Авдеева, Агицьдин и др., 2013].

Рассмотрим существующую систему подготовки кадров.

В целом организация обучения государственных гражданских служащих регламентируется нормами Федераль-

Фёдор Фёдорович Смирнов - аспирант, Среднерусский институт управления филиал РАНХиГС (302028, Россия, г. Орел, бульвар Победы, д. 5А). E-mail: politgmu@ mail.ru 
ного закона от 29 декабря 2012 г. № 273-ФЗ "Об образовании в Российской Федерации" и ст.ст. 60, 62, 63 и 71 Федерального закона от 27 июля 2004 г. № 79-Ф3 “О государственной гражданской службе Российской Федерации". Порядок получения образования и Государственные требования к профессиональной переподготовке и повышению квалификации государственных гражданских служащих Российской Федерации определены Указом Президента Российской Федерации от 28 декабря 2006 г. № 1474 «О дополнительном профессиональном образовании государственных гражданских служащих Российской Федерации" и постановлением Правительства Российской Федерации от 6 мая 2008 г. № 362.

В соответствии с Федеральным законом от 27 июля 2004 г. № 79-ФЗ «О государственной гражданской службе Российской Федерации" обучение служащих (профессиональная переподготовка и повышение квалификации) ежегодно организуется в рамках государственного заказа на дополнительное профессиональное образование гражданских служащих. При этом государственный заказ на дополнительное профессиональное образование федеральных гражданских служащих, вкцючая его объем и структуру, подготавливается Министерством труда России на основе предложений федеральных органов исполнительной власти и утверждается Правительством Российской Федерации после вступления в силу федерального закона о федеральном бюджете на соответствующий год.

Необходимость профессиональной переподготовки и повышения квалифрикации гражданских служащих отражается в их индивидуальных планах профессионального развития, и учитывается федеральными органами исполнительной власти при формировании предложений в государственный заказ.

Индивидуальный план разрабатывается гражданским служащим совместно с непосредственным руководителем в соответствии с должностным регламентом сроком на три года и вкАючает в себя:

- цель обучения;

- вид и форму получения дополнительного профессионального образования;

- направление дополнительного профессионального образования.

Сам по себе индивидуальный план способствует поддержанию и повышению у гражданского служащего необходимого уровня квалификации, а также получению в ходе обучения и профессиональной служебной деятельности знаний, умений, профессиональных навыков и качеств, необходимых для выполнения должностных обязанностей в соответствии с замещаемой должностью.

Таким образом, мы имеем общее понимание о том, как устроена система подготовки государственных гражданских служащих, какую правовую основу она имеет, а также какие документы являются базовыми дмя служащего при его обучении.

Говоря про систему подготовки сотрудников федеральных и региональных органов исполнительной власти и органов местного самоуправления, участвующих в реализации мероприятий по профилактике коррупции, то стоит обратить внимание на положение относительно нового Национального плана противодействия коррупции на 2018 2020 гг. (далее - Национальный план), который утвержден Указом Президента Российской Федерации 29 июня 2018 г. (№ 378). В данном документе предусмотрено следующее:

1. Мероприятия, предусмотренные Национальным планом, направлены на решение ряда задач, в том числе на повышение эффективности просветительских, образовательных и иных мероприятий, направленных на формирование антикоррупционного поведения государственных и муниципальных служащих, популяризацию в обществе антикоррупционных стандартов и развитие общественного правосознания. Таким образом, подразумевается, что система обучения сотрудников, участвующих в профимактике коррупции, уже суще- 
ствует и ее необходимо развивать.

2. K мерам по совершенствованию образовательных процессов в сфере антикоррупционной деятельности в Национальном плане относят:

- подготовку дополнительных профессиональных программ по вопросам противодействия коррупции;

- обеспечение ежегодного повышения квалификации федеральных государственных служащих, государственных гражданских служащих субъектов Российской Федерации, муниципальных служащих, в том числе впервые поступивших на службу для замещения должностей, вкАюченных в перечни, установленные нормативными правовыми актами Российской Федерации.

- включение в федеральные государственные образовательные стандарты общего образования, среднего профессионального и высшего образования поможений, предусматривающих формирование у обучающихся компетенции, позволяющей выработать нетерпимое отношение к коррупционному поведению, а в профессиональной деятельности - содействовать пресечению такого поведения;

- утверждение и реализацию программ по антикоррупционному просвещению обучающихся на 2018 - 2019 гг.

ГАавным элементом данного подхода является формирование единообразного понимания вопросов противодействия коррупции, создание организационных и учебно-методических основ повышения профессионализма сотрудников всех категорий, участвующих в данной работе [Гацко, 2015 ; Авакьян, Кененова, Ковмер и др., 2016].

Средствами же реализации данной задачи явцяются не только принятие и грамотная реализация соответствующих нормативных правовых актов, но и, прежде всего, выстраивание современной системы обучения на федеральном, региональном и муниципальном уровнях. Подразумевается, что повышение квалификации должно осуществляться в рамках государственного задания на оказание государственных услуг по реализации дополнительных профессиональных программ, устанавмиваемого Правительством Российской Федерации. Подготовка сотрудников указанной категории должна осуществцяться в рамках государственного заказа преимущественно на базе подведомственных Министерству образования и науки России образовательных организаций, филиалов Российской академии народного хозяйства и государственной служббы при Президенте Российской Федерации и региональных образовательных организаций.

Дия обеспечения образовательного процесса подготовки сотрудников, реамизующих профилактические мероприятия, Министерством науки и высшего образования России должна быть организована разработка и последующее утверждение соответствующих учебных программ, методических рекомендаций и пособий.

Изучив основу подготовки государственных гражданских служащих, а также положения Национального плана можно сделать вывод, что антикоррупционное обучение больше носит фрагментарный, незаконченный характер и не учитывает потребностей органов власти в профессиональном становмении соответствующих должностных миц. Такой вывод можно сдемать по тем мерам, которые предусмотрены Национальным планом, а также несоответствием существующей практики подготовки государственных гражданских служащих в целом системе подготовки сотрудников федеральных органов исполнительной власти, органов исполнительной власти субъектов Российской Федерации и органов местного самоуправления, ответственных за реализацию мероприятий по профилактике коррупции, в частности.

В первую очередь необходима организация на плановой и системной основе профессиональной подготовки и переподготовки государственных и муниципальных служащих в сфере противодействия коррупции, в том числе антикоррупционное обучение сотрудников кадровых подраздемений, непосредственно занимающихся профимак- 
тикой коррупции.

По мнению автора, подготовка сотрудников федерального, регионального и муниципального уровней, участвующих в рамках своих полномочий в противодействии коррупции, сможет реализоваться:

- в государственных образовательных организациях в рамках программ профессиональной переподготовки и повышения квалификации;

- на обучающих семинарах;

- на межведомственных учебнопрактических курсах;

- на учебно-методических сборах;

- на тренингах и в ходе деловых игр;

- в ходе проведения стажировок в компетентных органах вцасти, непосредственно занимающихся профилактикой коррупции, аппаратах администраций и органов вцасти субъектов Российской Федерации;

- в рамках наставничества при прибытии на государственную и муниципальную службу вновь назначенных сотрудников;

- в ходе самообучения, например посредством использования современных электронно-методических сборников материалов по вопросам профилактики коррупции, включающих в себя учебные наглядные пособия, систематизированные нормативные правовые акты в области противодействия коррупции; основные понятия, применяемые в сфере профилактики коррупции, и примерную тематику правового просвещения государственных и муниципальных служащих в указанной сфере; схемы, отображающие алгоритм

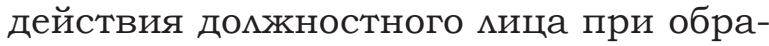
щении к нему каких-либо миц в целях склонения его к совершению коррупционных правонарушений, при предотвращении и урегулировании конфмикта интересов; порядок работы аттестационных комиссий.

В Национальном плане и в программах по антикоррупционному просвещению обучающихся на 2018 - 2019 годы большая часть таких форм не предусмотрена, при этом практически все они доказали свою эффективность в другой сфере общественных отношений, а именно - противодействии терроризму, где при координирующей роли Национального антитеррористического комитета создана система подготовки соответствующих кадров ${ }^{1}$.

Автором, с учетом уже имеющегося подхода к формированию системы антикоррупционного обучения, а также предусмотренных Национальным планом мер, выработаны дополнительные мероприятия по повышению эффективности профессиональной подготовки сотрудников фредерального, регионального и муниципального уровней, участвующих в рамках своих полномочий в противодействии коррупции.

Во-первых, в целях развития системы подготовки государственных и муниципальных служащих на всей территории страны на базе федеральных университетов могут быть созданы учебно-методические центры, осуществляющие методическое обеспечение деятельности субъектов по противодействию коррупции.

Посредством анкетирования государственных и муниципальных служащих в этих центрах могут выявляться недостатки в освоении отдельных направлений профессиональной переподготовки и повышения квалификации сотрудников, задействованных в сфере профилактики коррупции.

Во-вторых, для развития системы подготовки государственных и муниципальных служащих в настоящее время также необходимо фрормирование

\footnotetext{
${ }^{1}$ См. например: "В Москве прошло заседание Наиионального антитеррористического комитета, на котором расспотрены вопросы антитеррористической зашиты объектов транспортного перехода "Краснодарский край - Крым" и меры по её совершенствованию, а также некоторые аспекты подготовки государственных и мунииипальных служаших, участвуюших в профилактике терроризма" // офиииальный сайт HAK: http://nac.gov.ru/nak-prinimaet-resheniya/v-moskve-proshlozasedanie-nacionalnogo-11.html (дата обращения 05.09.18); Рогов А.С. Перспективные направления научного обеспечения правовой системы противодействия терроризму в российской федераиии / А.С. Рогов // Оперативник (сыщик). 2018. № 2 (55). C. 47-53; и др.
} 
единых теоретических и практических подходов к организации обучения, намаживание механизмов межведомственной координации, обновление учебно-методической базы, вкАючающей разработку и актуализацию программ подготовки кадров, внедрение дистанционных техномогий обучения, развитие научного обеспечения образовательного процесса в рамках исследования фимософских, идеологических, культурных, религиозных и иных течений, порождающих коррупцию.

В-третьих, с целью придать этому направлению законченный характер, целесообразно Федеральный закон от 25 декабря 2008 г. № 273-Ф3 «О противодействии коррупции» ${ }^{2}$ дополнить еще одной мерой в части, касающейся профессиональной подготовки и переподготовки государственных и муниципальных служащих по вопросам противодействия коррупции, повышения их квалификации на системной основе.

Данное направление обязательно должно учитываться и развиваться, так как "... предъявление квалификационных требований к гражданам, претендующим на замещение государственных или муниципальных должностей и должностей государственной или муници-

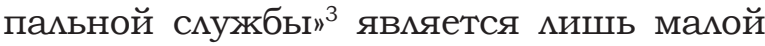
частью профессиональной компетенцией служащих. Иными словами, государственные и муниципальные служащие должны не только первично соответствовать предполагаемой должности при трудоустройстве, но и постоянно повышать свои навыки, знания и умения в профессиональной области, учитывать в своей работе изменения законодательства, а также принимать участие в становлении вновь пришедших на службу сотрудников (так называемое наставничество). Кроме этого, развитие данного направмения поможет более наглядно доводить полную и объективную информацию до всех, разъяснять действие отдельных механизмов и процедур.
Данное положение, по мнению автора, целесообразно отнести к отдельному пункту ст. 6 и представить с формулировками "организация профессиональной подготовки сотрудников федеральных органов исполнительной власти, органов исполнительной власти субъектов Российской Федерации и органов местного самоуправления, участвующих в рамках своих полномочий в противодействии коррупции" и "обеспечение процесса антикоррупционного обучения сотрудников федеральных органов исполнительной вцасти, органов исполнительной власти субъектов Российской Федерации и органов местного самоуправмения по вопросам противодействия коррупции".

В первом случае речь идет о сотрудниках кадровых подразделений, непосредственно занимающихся вопросами противодействия коррупции, во втором - о всех служащих без искАючения.

Таким образом, по мнению автора, должна получиться цельная система антикоррупционного обучения, которая будет способствовать общей эффективности и результативности деятельности по противодействию коррупции в России.

В первом случае речь идет о сотрудниках кадровых подразделений, непосредственно занимающихся вопросами противодействия коррупции, во втором - о всех служащих без исключения.

Таким образом, должна получиться цельная система антикоррупционного обучения, которая будет способствовать общей эффективности и результативности деятельности по противодействию коррупции в России.

\section{Список литературы:}

1. Гаико М. Ф. Антикоррупиионная политика государства: учебное пособие. Ногинск: Ногинский филиал РАНХиГС. 2015.

2. Авакьян С. А., Кененова И. П., Ковлер А. С. и др. Противодействие корруп-

\footnotetext{
${ }^{2}$ O противодействии коррупиии: Федеральный закон от 25 декабря 2008 г. № 273-ФЗ // Собрание законодательства Российской Федераиии. 2008. № 52 (ч. 1). Ст. 6228.

${ }^{3}$ Одна из мер, представленных в статье 6 Федерального закона от 25 декабря 2008 г. № 273-ФЗ "O противодействии коррупиии" (прим. автора).
} 
иии: конституиионно-правовые подходы: коллективная монография. М. : Юстииинформ, 2016.

3. Противодействие коррупиии: новые възовы : монография / Отв. ред. Т. Я. Хабриева. М., 2016.

4. Рогов A. C. Коррупиия в области осушествлениягосударственныхзакупок Министерством обороны Российской Федераиии как угроза экономической безопасности России // Научно-практическое u информаиионное издание "Юрист". 2011. № 5. C. 22-27.

5. Рогов А. С. Перспективные направления научного обеспечения правовой системь противодействия терроризму в российской федераиии // Оперативник (съииик). 2018. № 2 (55). C. 47-53.
6. Рогов А. С., Нестеров О. А. Конституиионный уровень правового регулирования противодействия коррупиии в Российской Федерайи // Власть. 2015. № 2. C. 182-184.

7. Сборник материалов Всероссийской научно-практической конферениии (19 апреля 2013 г., г. Хабаровск) / В. A. Авдеев, О. А. Авдеева, В. В. Агильдин и др.; под ред. Т. Б. Басовой, К. А. Волкова; Хабаровский краевой суд, Дальневосточнъий филиал Российской академии правосудия. Хабаровск. Юрист. 2013.

8. Шедий М. В. Причинные факторы, влияюшие на развитие коррупиионной преступности в современной России // Среднерусский вестник обиественных наук. 2010, № 1. С. 125-131.

\section{Библиографическое описание статьи}

Смирнов Ф. Ф. Совершенствование антикоррупционного обучения доцжностных миц // Власть и управление на Востоке России. 2018. № 3 (84). С. 142-148. DOI 10.22394/1818-4049-2018-84-3-142-148

Fyodor F. Smirnov - graduate student, the Central Russian institute of management - branch RANEPA (5A, Pobedy Boulevard, Oryol, 302028, Russian Federation). E-mail:

\section{About improvement of anti-corruption training of the officials}

In this article the author made an attempt to consider the current state of vocational training of public officials of the federal, regional and municipal levels participating within the powers in anti-corruption i.e. those who will organize and realize the relevant preventive activities (the staff of personnel divisions) and also other public officials fulfilling requirements of the anti-corruption legislation. On the basis of the existing positive experience of training in the sphere of counteraction to terrorism, the author developed the list of the directions, on which effective vocational training of employees of the federal, regional and municipal levels participating within the powers in anti-corruption is possible. The author offered updating of the current legislation in the part concerning the organization of vocational training of staff of federal organs of the executive authority, executive authorities of the territorial subjects of the Russian Federation and the local government bodies participating within the powers in anti-corruption.

Keywords: demand for credit, credits to individuals, economic growth, finance-growth nexus.

\section{References:}

1. Gacko M.F. Antikorrupcionnaja politika gosudarstva [Anti-corruption policy of the state]: uchebnoe posobie. Noginsk: Noginskij filial RANHiGS. 2015.

2. Avak'jan S. A., Kenenova I. P., Kovler A. S. i dr. Protivodejstvie korrupcii: konstitucionno-pravovye podhody [AntiCorruption: Constitutional and Legal Ap- proaches]: kollektivnaja monografija. M.: Justicinform, 2016.

3. Protivodejstvie korrupcii: novye vyzovy [Anti-Corruption: New Challenges]: monografija / Otv. red. T.Ja. Habrieva. M., 2016.

4. Rogov A. S. Korrupcija v oblasti osushhestvlenija gosudarstvennyh zakupok Ministerstvom oborony Rossijskoj Federacii kak ugroza jekonomicheskoj 
bezopasnosti Rossii [Corruption in the field of public procurement by the Ministry of Defense of the Russian Federation as a threat to the economic security of Russia //] // Nauchno-prakticheskoe $i$ informacionnoe izdanie "Jurist" [Scientific-practical and informational publication "Lawyer"]. 2011, no. 5, pp. 22-27.

5. Rogov A. S. Perspektivnye napravlenija nauchnogo obespechenija pravovoj sistemy protivodejstvija terrorizmu $v$ rossijskoj federacii [Perspective directions of scientific support of the legal system for countering terrorism in the Russian Federation] // Operativnik (syshhik) [Operative (detective)]. 2018, no. 2 (55), pp. 47-53.

6. Rogov A. S., Nesterov O. A. Konstitucionnyj uroven' pravovogo regulirovanija protivodejstvija korrupcii $v$ Rossijskoj
Federacii [The constitutional level of legal regulation of countering corruption in the Russian Federation] // Vlast' [Power]. 2015, no. 2, pp. 182-184.

7. Sbornik materialov Vserossijskoj nauchno-prakticheskoj konferencii (19 aprelja 2013 g., g. Habarovsk) / V.A. Avdeev, O.A. Avdeeva, V.V. Agil'din $i$ dr.; pod red. T.B. Basovoj, K.A. Volkova; Habarovskijkraevojsud,Dal'nevostochnyj filial Rossijskoj akademii pravosudija. Habarovsk. Jurist. 2013.

8. Shedij M. V. Prichinnye faktory, vlijajushhie na razvitie korrupcionnoj prestupnosti $v$ sovremennoj Rossii [Causal factors affecting the development of corruption crime in modern Russial // Srednerusskij vestnik obshhestvennyh nauk [Srednerussky Bulletin of Social Sciences]. 2010, no. 1, pp. 125-131.

\section{Reference to the article}

Smirnov F. F. About improvement of anti-corruption training of the officials // Power and Administration in the East of Russia. 2018. No. 3 (84). Pp. 142-148. DOI 10.22394/1818-4049-2018-84-3-142-148 